\title{
Lithothamnion muelleri Controls Inflammatory Responses, Target Organ Injury and Lethality Associated with Graft-versus-Host Disease in Mice
}

\author{
Barbara M. Rezende ${ }^{1, \dagger}$, Priscila T. T. Bernardes ${ }^{1, \dagger}$, Carolina B. Resende ${ }^{1}$, \\ Rosa M. E. Arantes ${ }^{2}$, Danielle G. Souza ${ }^{3}$, Fernão C. Braga ${ }^{4}$, Marina G. M. Castor ${ }^{1}$, \\ Mauro M. Teixeira ${ }^{5}$ and Vanessa Pinho ${ }^{1, *}$
}

1 Laboratory of Resolution of Inflammatory Response, Department of Morphology, Institute of Biological Sciences, Federal University of Minas Gerais, Belo Horizonte, 31270-901, Brazil; E-Mails: babirez@hotmail.com (B.M.R.); priscilattb@yahoo.com.br (P.T.T.B.); carolbresende@gmail.com (C.B.R.); marinacastor@gmail.com (M.G.M.C.)

2 Laboratory of Experimental Neuro-Immunopathology, Department of Pathology, Institute of Biological Sciences, Federal University of Minas Gerais, Belo Horizonte, 31270-901, Brazil; E-Mail: rosa@icb.ufmg.br

3 Host-Microbes Interaction Laboratory, Department of Microbiology, Institute of Biological Sciences, Federal University of Minas Gerais, Belo Horizonte, 31270-901, Brazil;

E-Mail: souzadg@gmail.com

4 Department of Pharmaceutical Products, Faculty of Pharmacy, Federal University of Minas Gerais, Belo Horizonte, 31270-901, Brazil; E-Mail: fernao@netuno.lcc.ufmg.br

5 Immunopharmacology, Department of Biochemistry and Immunology, Institute of Biological Sciences, Federal University of Minas Gerais, Belo Horizonte, 31270-901, Brazil;

E-Mail: mmtex.ufmg@gmail.com

$\dagger$ These authors contributed equally to this work.

* Author to whom correspondence should be addressed; E-Mail: vpinhos@gmail.com; Tel./Fax: +55-31-3409-2996.

Received: 3 May 2013; in revised form: 1 July 2013 / Accepted: 2 July 2013 /

Published: 18 July 2013

Abstract: Lithothamnion muelleri (Hapalidiaceae) is a marine red alga, which is a member of a group of algae with anti-inflammatory, antitumor, and immunomodulatory properties. The present study evaluated the effects of treatment with Lithothamnion muelleri extract (LM) in a model of acute graft-versus-host disease (GVHD), using a model of adoptive 
splenocyte transfer from $\mathrm{C} 57 \mathrm{BL} / 6$ donors into B6D2F1 recipient mice. Mice treated with LM showed reduced clinical signs of disease and mortality when compared with untreated mice. LM-treated mice had reduced tissue injury, less bacterial translocation, and decreased levels of proinflammatory cytokines and chemokines (interferon- $\gamma$ (IFN- $\gamma$ ), tumor necrosis factor- $\alpha$ (TNF- $\alpha$ ), chemokine (C-C motif) ligand 2 (CCL2), chemokine (C-C motif) ligand 3 (CCL3) and chemokine (C-C motif) ligand 5 (CCL5)). The polysaccharide-rich fraction derived from LM could inhibit leukocyte rolling and adhesion in intestinal venules, as assessed by intravital microscopy. LM treatment did not impair the beneficial effects of graft-versus-leukaemia (GVL). Altogether, our studies suggest that treatment with Lithothamnion muelleri has a potential therapeutic application in GVHD treatment.

Keywords: algae; chemokine; cytokine; GVHD; inflammation

\section{Introduction}

Allogeneic haematopoietic stem cell transplantation (HSCT) remains the major curative therapy for several haematological diseases [1,2]. The main complication from this therapy is graft-versus-host disease (GVHD), an immunological disorder with high morbidity and mortality [1,2]. The pathogenesis of GVHD is associated with immunocompetent donor cells that become activated upon recognition of antigens from the immunocompromised host and subsequently reject target host organs such as the lung, liver, and intestine $[1,3,4]$.

Steroids such as methylprednisolone or prednisone are the first-line treatment for GVHD because they have broad anti-inflammatory and lymphocytotoxic effects [5,6]. However, steroid-refractory GVHD patients are at high risk of death from the disease or related complications, and there is no standard treatment strategy for these patients. Currently, some drugs that primarily interfere with the activation and signaling pathways of T cells, antigen-presenting cells, B cells, and NK cells, such as sirolimus and alemtuzumab, have been employed as second-line treatment for acute graft-versus-host disease [6-8]. Other drugs, such as infliximab and etanercept, act against pro-inflammatory cytokines or their receptors to modify inflammatory responses [6-8]. However, most of the available treatments only induce clinical benefits in a limited subset of patients [5]. Few studies have investigated complementary medicine for the treatment of GVHD.

Recent evidence has indicated that exacerbated immune responses and associated complications can be alleviated with the use of natural products from marine species, including compounds isolated from marine algae [9]. Given the relevance of these findings, the evaluation of biological activities of algae extracts and derived compounds is a valid strategy for drug development.

Lithothamnion muelleri Lenormand ex Rosanoff (Hapalidiaceae) is a red seaweed found in Brazilian coastal areas and is rich in minerals like calcium carbonate and sulphated polysaccharides, and is potentially bioactive [10-12]. We have recently reported the reduction of leukocyte rolling induced by polysaccharide-rich fractions from L. muelleri [12]. Moreover, some studies have demonstrated the biological effects of other algae of the genus Lithothamnion, including the inhibition 
of polyp formation and inflammation in the gastrointestinal tract [13], and protection against formation of liver tumors in mice fed with a high-fat diet [14]. The present study suggests that treatment with Lithothamnion muelleri extract (LM) may be a potential new therapy to control inflammatory responses, tissue injuries, and lethality associated with graft-versus-host disease.

\section{Results and Discussion}

\subsection{LM Treatment Reduced Intestinal and Hepatic Injury in Mice Subjected to GVHD}

To verify the possible therapeutic properties of L. muelleri in GVHD, this disease was induced by transfer of splenocytes from C57BL/6J donors to B6D2F1 mice. Mice subjected to GVHD and not treated were considered the GVHD group. The LM group was subjected to GVHD and treated with $1 \% \mathrm{LM}$ in the $\operatorname{diet}(\mathrm{w} / \mathrm{w})$. In a dose-response experiment, the dose of $1 \% \mathrm{LM}$ in the diet (w/w) was found to be optimal for inhibiting GVHD and was chosen for subsequent experiments (Supplementary Figure S1).

Intestine and liver sections were evaluated at days 3, 10, and 20 after transplantation. In the GVHD group, at days 3 and 10 there was mild histopathological injury associated with oedema, congestion of the lamina propria, and increased cellularity associated with focal areas of villous enlargement. Additionally, there was mild focal infiltration in the muscular and serous layers. At these time-points, there were no differences in mice subjected to GVHD, regardless of LM treatment (data not shown).

At day 20 after transplantation, there was partial loss of organ architecture, increased cellularity, oedema, and congestion in the intestine of animals that had been subjected to GVHD. Severe degenerative changes, ulcerations of the mucosa, and areas of focal necrosis in the muscular and serous layers were also observed at this time-point (Figure 1A,E). LM treatment significantly ameliorated the overall pathological scores. Changes in organ architecture were decreased and were characterized by superficial and rare erosions in the mucosa, reduced inflammatory infiltration and oedema in the lamina propria, and preserved muscular and serous layers (Figure 1A,F).

The mucus layer is considered to be the first line of defense between bacteria in the lumen and host cells, and also serves as the initiation surface for host-microbe interactions [15-17]. The major components of mucus are mucins, a family of heavily glycosylated proteins [15-17]. As observed in Figures 1B,H, there was reduction in the number of goblet cells in the GVHD group, as determined by Periodic Acid-Schiff (PAS) staining, which acts as a marker for mucin. In contrast, LM treatment maintained the number of goblet cells at a level similar to that of the control group (Figure 1B,G,I), which might have contributed to the intestinal protection afforded by LM.

There were few alterations in the liver at day three after transplantation in the GVHD group (data not shown). At day 10, the GVHD group presented with discreet oedema and increased cellularity in the parenchyma and periportal areas. The latter parameters were not modified by LM treatment (data not shown). However, at day 20 after transplantation, there was significant injury throughout the liver parenchyma (Figure $1 \mathrm{C}, \mathrm{K}$ ). Increased inflammatory infiltration was observed mainly in the periportal areas and vasodilatation, hepatocyte necrosis, and diffuse vacuolisation were also observed (Figure 1K). There was significant preservation of hepatic tissue with mild oedema and decreased inflammatory cell accumulation in the LM group (Figure 1C,L). Other Lithothamnion 
species, including L. calcareum [13] and a mixture of L. calcareum and L. coraloides [18] have also been shown to reduce intestinal and hepatic injury in other models of inflammation. Of interest, $50 \%$ of patients who developed GVHD also develop hepatic and intestinal injuries [19]. Therefore, LM-induced protection against severe liver and intestinal damage may be eventually exploited in the clinical setting.

Figure 1. Lithothamnion muelleri extract (LM) treatment reduces intestinal and hepatic injury in mice subjected to GVHD. GVHD was induced by the adoptive transfer of splenocytes from $\mathrm{C} 57 \mathrm{BL} / 6 \mathrm{~J}$ donors to $\mathrm{B} 6 \mathrm{D} 2 \mathrm{~F} 1$ mice. Mice that received syngeneic (B6D2F1) splenocytes did not develop disease and were considered the Control group. LM $(1 \%$ in the diet, $\mathrm{w} / \mathrm{w})$ was offered in the diet of recipient mice from one day before transplantation until the experimental endpoint. At day 20 after transplantation, the mice were sacrificed and the jejunum-ileum and liver tissues were sampled for histopathological analysis (A and $\mathbf{C}$ ). The numbers of PAS-positive goblet cells counted at $40 \times /$ field were determined from four fields per intestine section (B). D-F, histological aspects of H\&E-stained small intestine sections in Control, GVHD, and LM-treated mice, respectively. Scale bar, $50 \mu \mathrm{m}$ for all panels. G-I, intestine sections with PAS-positive goblet cells from Control, GVHD, and LM treated mice, respectively. $\mathbf{J}-\mathbf{L}$, histological aspects of H\&E-stained liver sections from Control, GVHD, and LM treated mice, respectively. Scale bar, $20 \mu \mathrm{m}$ for all panels. The results are presented as the mean \pm SEM $(n=6) ; *$ and ${ }^{\#}, p<0.05$ when compared with the Control and GVHD groups, respectively.
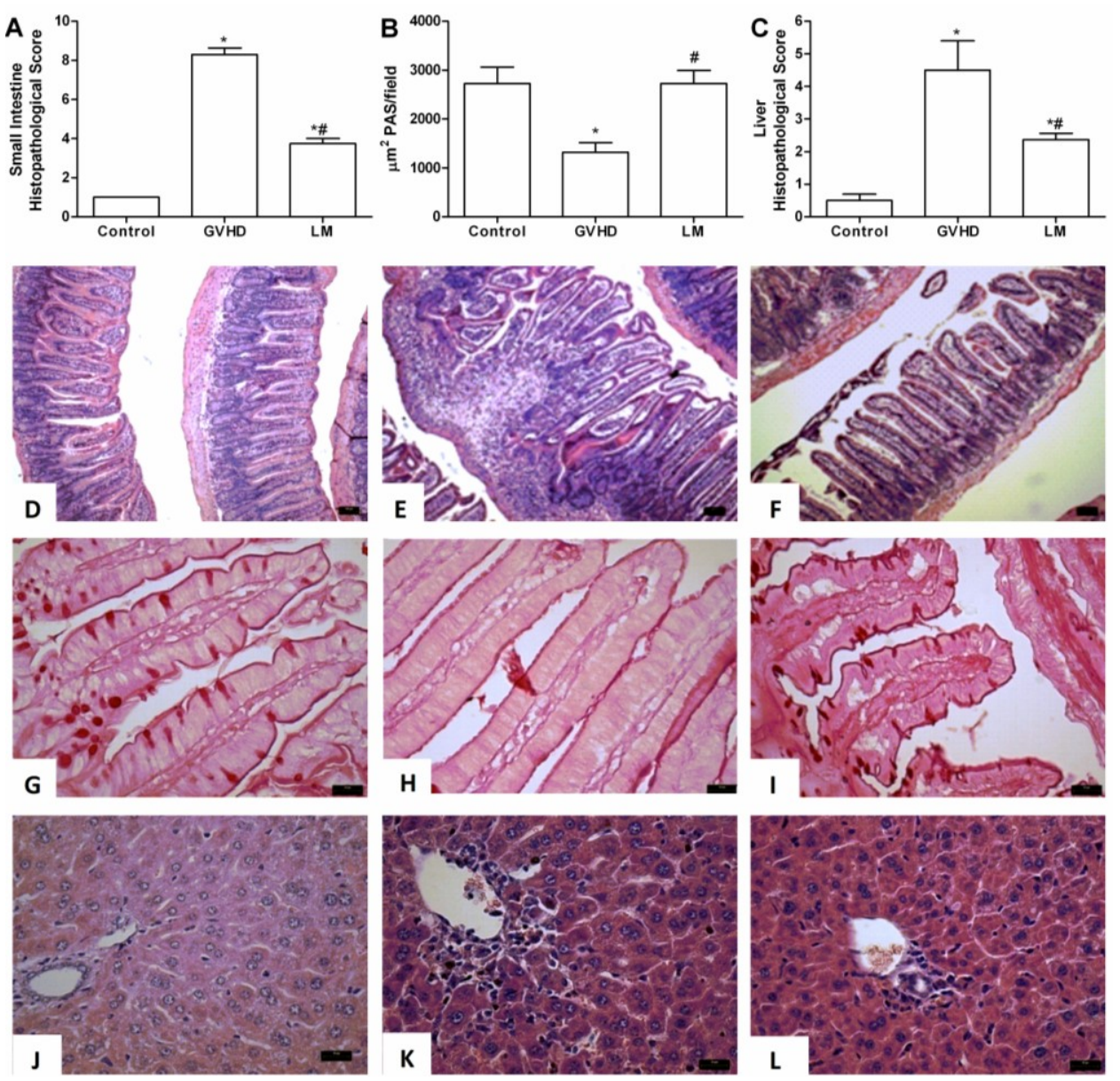


\subsection{LM Treatment Reduced Bacterial Translocation and Macrophage Accumulation in Mice Subjected} to GVHD

Differences between the treated and untreated groups were more evident at day 20 after transplantation. Therefore, all subsequent evaluations were carried out at this time-point. Although there is much liver damage [20], clinical and experimental evidence suggests that the intestine is the main organ related to the pathophysiology of GVHD and contributes significantly to causing systemic disease [21]. Intestinal injury is associated with bacterial translocation to the liver and subsequently into the bloodstream, leading to sepsis [22-25]. At day 20 after transplantation, high number of bacteria was observed in the peritoneal lavage fluid from the GVHD group (Figure 2A). Bacterial levels were also increased in the liver and blood of animals subjected to GVHD (Figure 2B,C). In contrast, fewer bacteria were observed in the peritoneal cavity, liver, and blood of LM-treated mice that were subjected to GVHD, which was reflected by the overall amelioration of the disease (Figure 2A-C). This is an important finding as endotoxin has been identified as a major mediator of intestinal and systemic inflammation in murine GVHD [23,26]. Moreover, as observed previously, there was a reduction of the intestinal mucus layer in the GVHD group and this layer was significantly preserved after LM treatment (Figure 1B,H,I). Mucin degradation by bacteria often occurs during the initial stages of some intestinal diseases and can modify the protection of the host mucosal surfaces [15-17,27]. In this context, the preservation of the mucus layer in LM-treated mice might have contributed to effective intestinal protection and might also have been associated with reduced bacterial translocation. In fact, bacterial translocation and sepsis are important causes of death in GVHD patients [25].

There were high number of macrophages in the intestine and liver of mice subjected to GVHD (Figure 2D,E). In LM-treated mice, macrophage infiltration in the jejunum ileum and liver was reduced (Figure 2D,E). This result is relevant because macrophages are important for GVHD development. These cells are recruited to target organs, have phagocytic functions, participate in antigen presentation to $\mathrm{T}$ lymphocytes, and produce inflammatory mediators, including reactive oxygen species, chemokines, and cytokines [28]. Therefore, the reduction of macrophages observed in the LM group may be associated with protection from GVHD. 
Figure 2. Lithothamnion muelleri extract (LM) treatment inhibits bacterial translocation and macrophage accumulation in target organs and blood of mice subjected to GVHD. GVHD was induced by the transfer of splenocytes from C57BL/6J donors to B6D2F1 mice. Mice that received syngeneic (B6D2F1) splenocytes did not develop disease and were considered the Control group. LM (1\% in the diet, w/w) was offered in the diet of recipient mice from one day before transplantation until the experimental endpoint. At day 20 after transplantation, the mice were sacrificed and the bacterial translocation to the peritoneal cavity (A), blood (B), and liver (C) were quantified. Macrophages were quantified in the jejunum-ileum (D) and liver (E) by enzymatic methods. The results are presented as the mean $\pm \operatorname{SEM}(n=6) ;{ }^{*}$ and ${ }^{\#}, p<0.05$ when compared with the Control and GVHD groups, respectively.
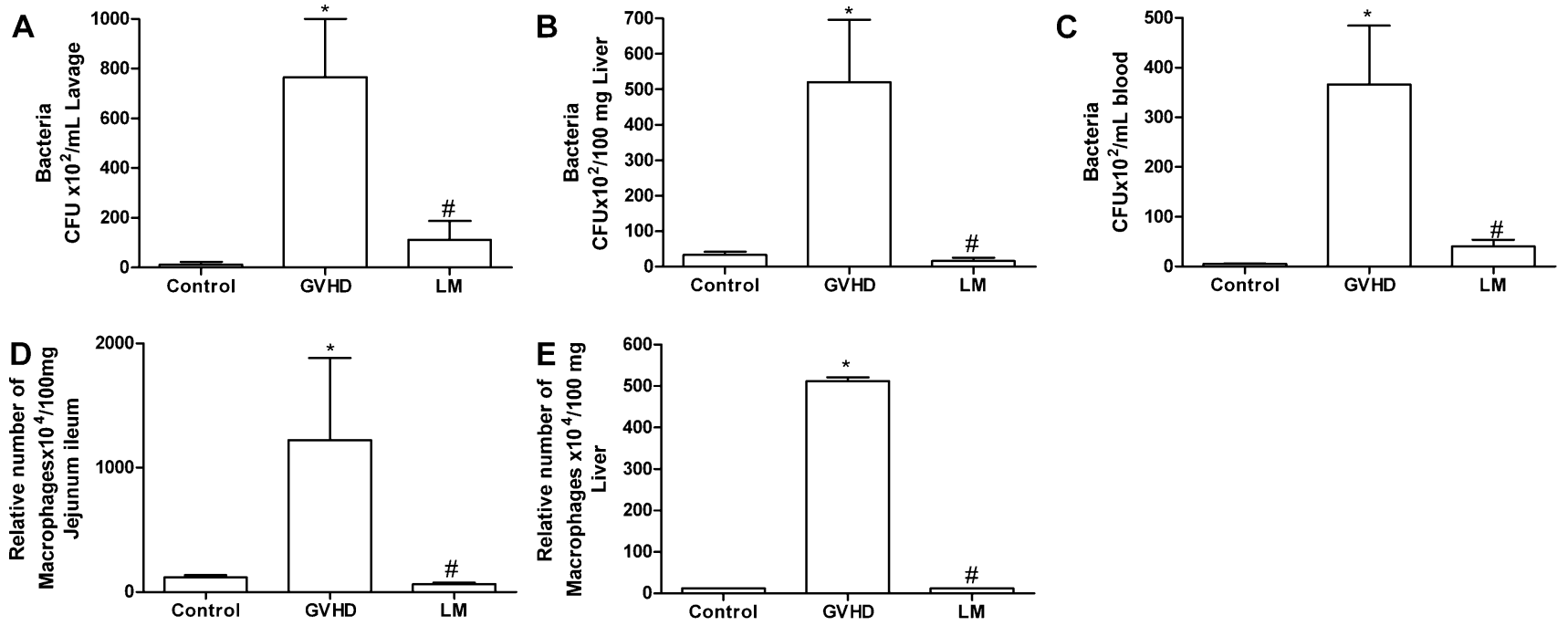

\subsection{LM Treatment Reduced the Production of Chemokines and Proinflammatory Cytokines in the} Intestines and Livers of GVHD Mice

GVHD is associated with increased levels of pro-inflammatory mediators in the target organs. Herein, there were increased levels of CCL2, CCL5, TNF- $\alpha$, and IFN- $\gamma$ in the intestine of mice subjected to GVHD, mainly at 20 days after transplantation (Figure 3). LM treatment substantially decreased the production of cytokines and chemokines at that time-point. 
Figure 3. Lithothamnion muelleri extract (LM) treatment reduces the concentrations of cytokines and chemokines in the small intestine of mice subjected to GVHD. GVHD was induced by the transfer of splenocytes from C57BL/6J donors to B6D2F1 mice. Mice that received syngeneic (B6D2F1) splenocytes did not develop disease and were considered the Control group. LM (1\% in the diet, w/w) was offered in the diets of recipient mice from 1 day before transplantation until the experimental endpoint. At 20 days after transplantation, the mice were sacrificed and the concentrations of CCL2 (A), CCL5 (B), TNF- $\alpha$ (C) and IFN- $\gamma$ (D) in the intestinal homogenates were evaluated by Enzyme Linked Immuno Sorbent Assay (ELISA). The results are shown as the mean $\pm \operatorname{SEM}(n=5)$; * and *, $p<0.05$ when compared with the Control and GVHD groups, respectively.
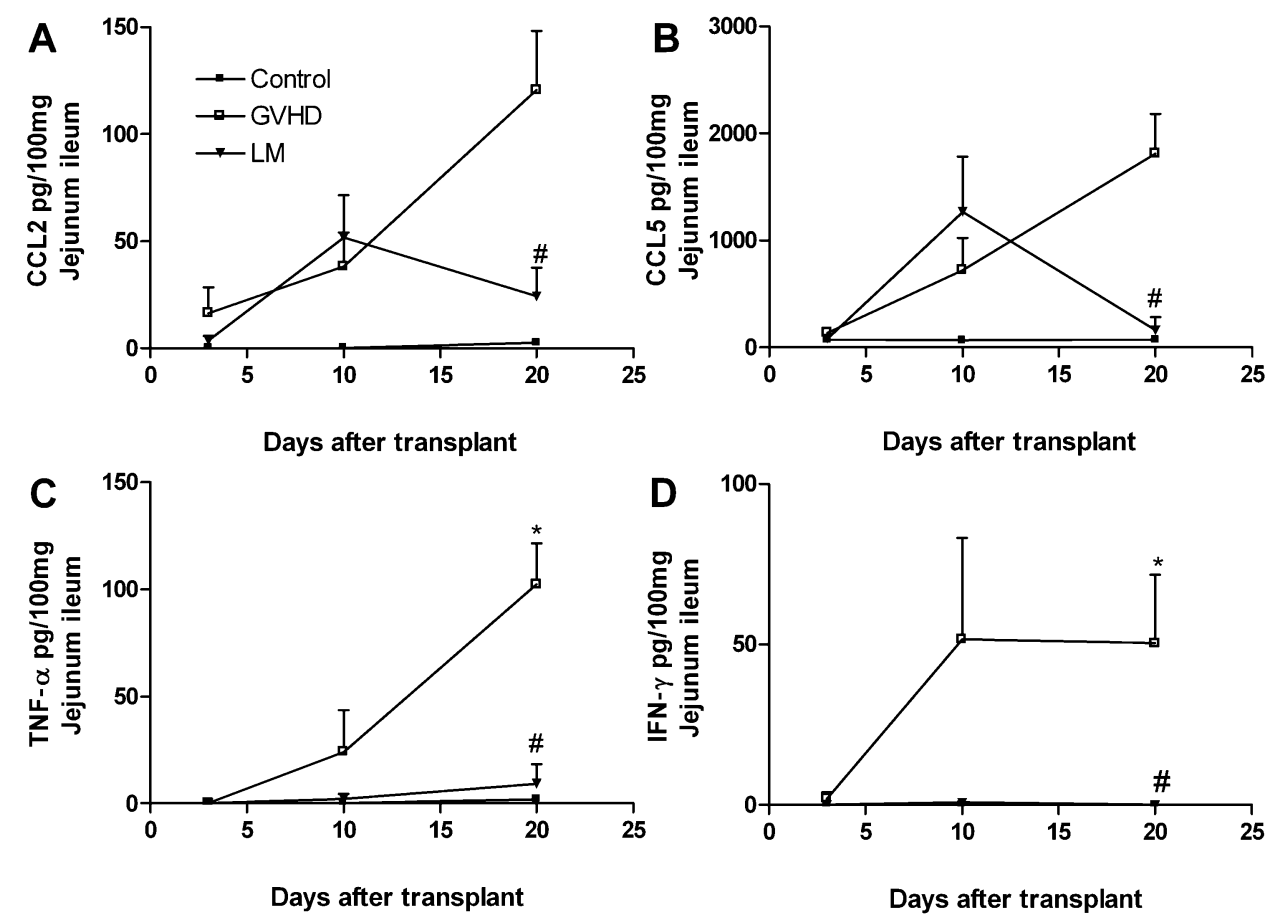

There were also increased levels of the chemokines CCL3 and CCL5 and of the cytokine TNF- $\alpha$ in the liver of mice subjected to GVHD at day 20 after transplantation (Figure 4), although no significant differences was observed between the levels of CCL2 and IFN- $\gamma$ in the liver of LM-treated and untreated mice subjected to GVHD (Supplementary Figure S2). LM treatment completely inhibited TNF- $\alpha$ production and reduced CCL5 and CCL3 production (Figure 4A-C). The increased macrophage accumulation in the intestine and liver of GVHD mice observed previously in this work might be secondary to the production of CCL2, CCL3, and CCL5, which were observed in GVHD group, as these chemokines are known chemoattractants of macrophages and T cells. Macrophages can also produce such cytokines and chemokines to perpetuate the inflammatory process observed in GVHD [29-37]. Previously, our group reported that intestinal CCL2 levels were increased from the early stages of GVHD [35]. Moreover, the interaction of CCL2 with its receptor facilitates the activation and migration of $\mathrm{CD}^{+} \mathrm{T}$ lymphocytes to GVHD target organs [38]. CCL3 is another important chemokine in GVHD. Recent studies have demonstrated that the absence of CCL3 in the donor cells or the pharmacological blockade of the CCL3 receptor reduces GVHD-associated mortality and target organ damage, reduces the accumulation of $\mathrm{CD}^{+}$and $\mathrm{CD} 8^{+} \mathrm{T}$ lymphocytes in the spleen 
and intestine, and inhibits the recruitment of macrophages to the intestines [29,34]. Furthermore, the neutralisation of CCL3 was associated with reduced levels of CCL5 in the intestines of GVHD mice, which suggested that CCL3 could modulate CCL5 levels in this organ [34]. The absence of the CCL5 receptor was also associated with improved survival, reduced clinical disease, reduced levels of TNF- $\alpha$ and IFN- $\gamma$, and the reduced recruitment of inflammatory cells such as $\mathrm{T}$ lymphocytes and mononuclear cells to the GVHD target organs [32]. IFN- $\gamma$ and TNF- $\alpha$ are well-known to have relevant roles in GVHD [19]. Increased levels of these cytokines precede clinical GVHD symptoms and are associated with a systemic syndrome of weight loss, diarrhea, skin changes, and high mortality [39-42]. We also observed increased levels of these cytokines at day 10 after transplantation in GVHD mice; this finding coincided with the onset of clinical disease and subsequent mortality as seen below. On the other hand, LM-treated GVHD mice presented with reduced levels of IFN- $\gamma$ and TNF- $\alpha$, which might have contributed to the protection of the target organs and reduced GVHD-associated mortality. In this context, we suggest that the reduced levels of chemokines and cytokines that are associated with reduced macrophage accumulation might have contributed to the reduced inflammatory responses in LM-treated GVHD mice.

Figure 4. Lithothamnion muelleri extract (LM) treatment reduces the concentrations of cytokines and chemokines in the liver of mice subjected to GVHD. GVHD was induced by the transfer of splenocytes from $\mathrm{C} 57 \mathrm{BL} / 6 \mathrm{~J}$ donors to B6D2F1 mice. Mice that received syngeneic (B6D2F1) splenocytes did not develop disease and were considered the Control group. LM ( $1 \%$ in the diet, $\mathrm{w} / \mathrm{w})$ was offered in the diets of recipient mice from one day before transplantation until the experimental endpoint. At 20 days after transplantation, the mice were sacrificed and the concentrations of CCL3 (A), CCL5 (B), and TNF- $\alpha(\mathbf{C})$ in the liver homogenates were evaluated by ELISA. The results are shown as the mean \pm SEM $(n=5) ; *$ and ${ }^{\#}, p<0.05$ when compared with the Control and GVHD groups, respectively.
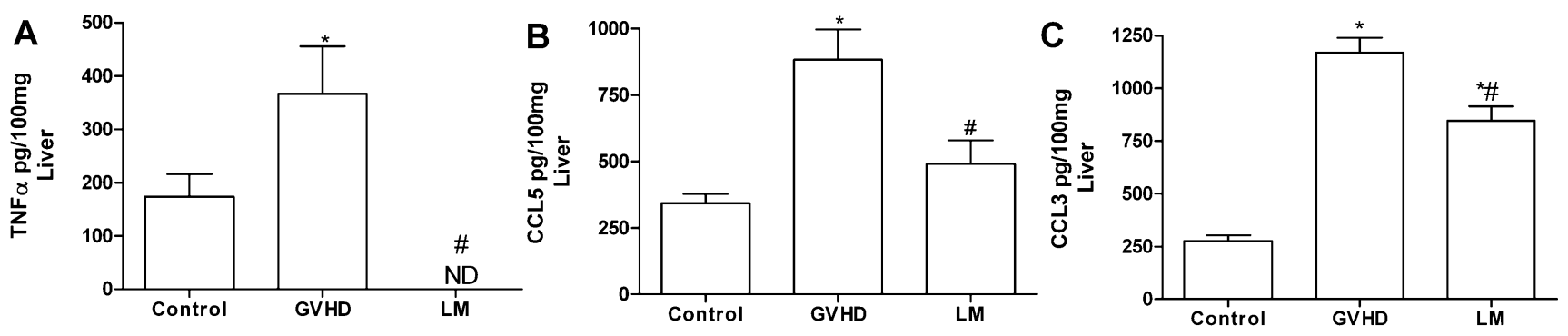

2.4. Polysaccharide-Rich Fraction of L. muelleri Inhibited Leukocyte-Endothelial Cell Interactions in the Intestinal Microvasculature of GVHD Mice

L. muelleri is composed mainly of calcium carbonate $\left(\mathrm{CaCO}_{3}\right)$, which represents $80 \%-90 \%$ of its biomass [43]. Recent studies with Lithothamnion species have demonstrated the capacity of these algae to suppress intestinal polyp formation and reduce gastrointestinal inflammation induced in animals fed a high-fat diet. In these studies, the mechanism behind the protective effect of algae is associated with the activity of their mineral constituents, including $\mathrm{CaCO}_{3}$ [13,44]. Thus, the effects of $\mathrm{CaCO}_{3}$ on GVHD were investigated and compared to LM treatment (Supplementary Figure S3). To assess this, GVHD was induced and mice were given normal chow (GVHD group) or treated with 
$1 \% \mathrm{LM}$ (LM group) or with $0.9 \% \mathrm{CaCO}_{3}\left(\mathrm{CaCO}_{3}\right.$ group) in the diet. $\mathrm{CaCO}_{3}$ did not recapitulate the protective mechanisms of LM treatment in GVHD. Indeed, weight loss and clinical score were similar mice given $\mathrm{CaCO}_{3}$ and the control group, whereas LM treatment reduced disease significantly in the same experiment. Therefore, other constituents of LM appear to be associated with GVHD protection. Some polysaccharide-rich fractions have been recently obtained from the species and characterized by Soares et al. (2012) [12]. Here, intravenous injections of LM fractions reduced lipopolysaccharide-induced leukocyte rolling in mice by approximately 90\% [12]. Currently, it is known that sulphated polysaccharides from seaweed have important biological properties such as anticoagulant, antioxidant, antitumor, antiviral, and anti-inflammatory activities [45,46]. Thus, we assessed whether LM polysaccharides (B2 fraction) could interfere directly with the initial stages of leukocyte migration to the GVHD target organs (B2 group). We performed intravital microscopy on the intestinal postcapillary venules of animals subjected to GVHD at day 10 after transplantation. The mice were treated with $\mathrm{B} 2$ at $30 \mathrm{~min}$ before the microscopic analysis. As seen in Figure 5, B2 treatment reduced the numbers of both rolling and mesenteric venule-adherent leukocytes. LM fractions-induced decreases in leukocyte rolling and adhesion could explain the reduced levels of inflammatory infiltration into the evaluated target organs as well as the control of GVHD-associated inflammatory responses.

Figure 5. Treatment with a polysaccharide fraction of Lithothamnion muelleri extract (LM) decreases the number of rolling and adherent leukocytes in the mesenteric vasculature of mice subjected to GVHD. GVHD was induced by the transfer of splenocytes from $\mathrm{C} 57 \mathrm{BL} / 6 \mathrm{~J}$ donors to B6D2F1 mice. Mice that received syngeneic (B6D2F1) splenocytes did not develop disease and were considered the Control group. At day 10 after transplantation, the mice were anesthetized and intestinal venules $( \pm 40 \mu \mathrm{m})$ were selected in which to count the numbers of rolling and adherent leukocytes by intravital microscopy. Mice that received C57BL/6J splenocytes were treated either with the vehicle or with a polysaccharide fraction of $\mathrm{LM}(\mathrm{B} 2,100 \mathrm{mg} / \mathrm{kg})$ at $30 \mathrm{~min}$ before intravital microscopy. (A) Number of rolling cells/minute; (B) Number of adherent cells/100 $\mu \mathrm{m}$ is presented as the mean \pm SEM $(n=7-16)$. Control group $(\bullet)$, GVHD group $(\boldsymbol{\Delta})$ and B2 group $(\bullet)$. * and ${ }^{\#}, p<0.05$ when compared with the Control and GVHD groups, respectively.
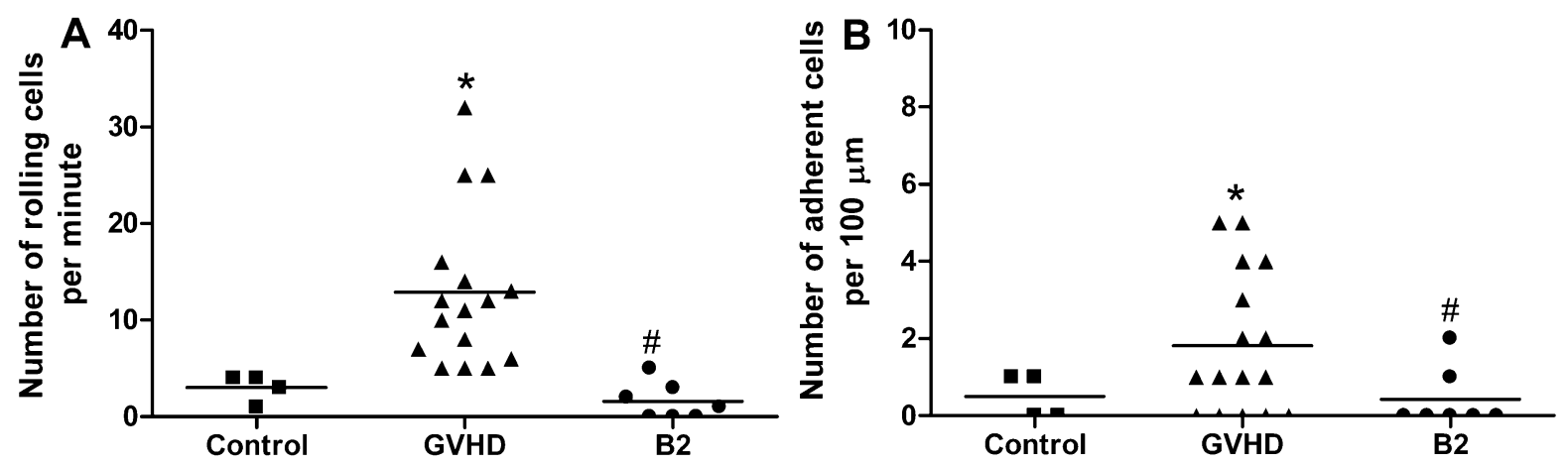


\subsection{LM Treatment Reduced Clinical Disease and Mortality in Mice Subjected to GVHD}

Some hallmark features of GVHD include mortality, weight loss and clinical signs such as a loss of skin integrity and fur texture and diarrhea and occult blood in the faeces $[47,48]$. We therefore evaluated whether LM treatment could prevent GVHD-associated mortality. As shown in Figure 6A, all B6D2F1 mice that received splenocytes from $\mathrm{C} 57 \mathrm{BL} / 6 \mathrm{~J}$ mice and were not treated (GVHD group) died before day 22. This mortality was associated with significant weight losses and high clinical scores. The control group did not develop GVHD and thus all mice were alive at the end of the experiment. The remaining mice were killed on day 40, which was the last day of observation. B6D2F1 mice that received splenocytes from C57BL/6J mice and were treated with LM (LM group) had prolonged survival and reduced, both, weight losses and clinical scores (Figure 6A-C). Of note, LM-treated animals that were not subjected to GVHD induction (Control + LM group) had the same survival rate, weight gain, and clinical score as the control animals (Figure 6); these data indicate that treatment with L. muelleri alone did not affect the analyzed parameters. These data are consistent with our previous results that demonstrated reduced target organ injury and lower GVHD-associated inflammatory responses, which ultimately led to significantly improved survival rates in LM-treated mice.

Figure 6. Lithothamnion muelleri extract (LM) treatment decreases death, weight loss, and clinical signs in mice subjected to GVHD. GVHD was induced by the transfer of splenocytes from $\mathrm{C} 57 \mathrm{BL} / 6 \mathrm{~J}$ donors to $\mathrm{B} 6 \mathrm{D} 2 \mathrm{~F} 1$ mice. Mice that received syngeneic (B6D2F1) splenocytes did not develop disease and were considered the Control group. LM $(1 \%$ in the diet, $\mathrm{w} / \mathrm{w})$ was offered in the diets of recipient mice from one day before transplantation until the experimental endpoint. After the induction of GVHD, the mice were evaluated every two days for survival (A), body weight (B), and clinical scoring (C). The results are shown as the mean \pm SEM and the numbers of animals were as follows: Control group ( $\bullet), n=6$; Control + LM group ( $\square), n=6$; GVHD group (घ), $n=7$ and LM group $(\boldsymbol{\nabla}), n=7 . *$ and ${ }^{\#}, p<0.05$ when compared with the Control and GVHD groups, respectively.
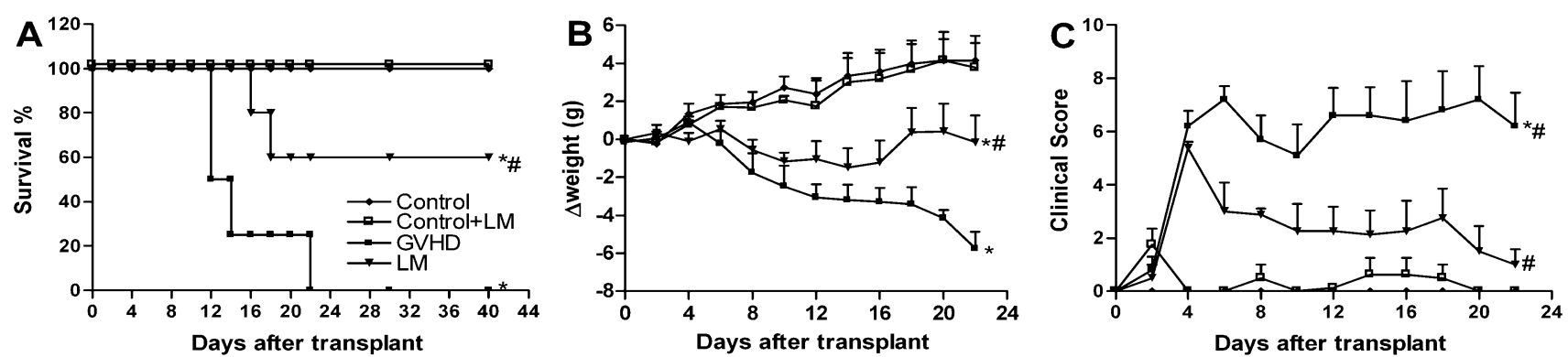

Different animal models of GVHD have been used since the 1970s. These models are useful for understanding the mechanisms involved in GVHD-associated inflammatory responses and for the development of new therapeutic strategies [49]. The induction of acute GVHD in mice involves the transplantation of splenocytes and/or bone marrow cells and can vary, depending on the dose of radiation used to ablate the immune cells of the receptor. In partial body irradiation, also known as the non-myeloablative regimen, it is not necessary to completely reconstitute the bone marrow. After 
transplantation, mice demonstrate chimerism, in which most of the cells are donor-derived [37,42]. The total body irradiation model, also known as the myeloablative regimen, requires an infusion of bone marrow precursor cells for replenishment [37,42]. When combined with the transplantation of bone marrow cells and splenocytes, models that employ total body irradiation result in more severe disease. The irradiation dose is proportional to the degrees of tissue damage and subsequent cytokine production that are observed during the conditioning regimen, and these factors can influence the development of GVHD [42]. Thus, to confirm the beneficial effects of LM treatment in graft-versus-host disease and to establish relevance to the human disease, we tested LM treatment in mice that had been subjected to total body irradiation as described in the Materials and Methods. LM treatment was also protective in this model (Supplementary Figure S4), which highlights the effectiveness and relevance of LM treatment that we have observed.

\subsection{Treatment with LM Decreased GVHD but Did Not Interfere with GVL Response}

Several therapies that are effective in preventing GVHD usually lead to reduced graft-versus-leukaemia activity (GVL), which is the ability of donor-derived infused lymphocytes in a haematopoietic stem cell-transplanted patient to react against leukemic cells, invalidating their effective applications [50-53]. Graft-versus-host disease typically correlates with desired GVL reactivity [54-56]. Thus, we assessed whether LM treatment could interfere with beneficial graft-versus-leukaemia response. To determine this, GVHD was induced by a transfer of allogeneic splenocytes from $\mathrm{C} 57 \mathrm{BL} / 6 \mathrm{~J}$ to $\mathrm{B} 6 \mathrm{D} 2 \mathrm{~F} 1$ mice. The control group received a transfer of syngeneic splenocytes from B6D2F1 mice. Mice that were subjected to GVHD were treated or not with LM (LM group and GVHD group, respectively). To verify the GVL response, the GVHD mice were injected with $10^{4} \mathrm{GFP}^{+} \mathrm{P} 815$ cells immediately after splenocytes transplantation at day 0 and were not treated (GVHD + P815 group). One group of GVHD mice that received GFP ${ }^{+}$P815 cells had been treated with LM, which was offered in the diet from one day before transplant until the end of the experiment (GVHD + LM + P815 group). Finally, to verify the viability of the P815 cells, one group of mice received only the P815 injection and was not subjected to GVHD (P815 group). Mice were monitored every two days for survival. Mice in the control group did not develop GVHD and there were no deaths in this group. The mice that had been subjected to GVHD and were not treated with LM (GVHD group) died until 25 days after transplantation. The mice that received only tumor cells (P815 group) presented with 100\% lethality at day 24 after transplantation, which indicated the viability of the tumor cells. GVHD mice that received P815 cells remained alive until 35 days after transplantation. Thus, the GVHD mice that received P815 cells died from GVHD rather than from the tumor. LM treatment reduced the severity of GVHD without interfering with the beneficial responses of the allogeneic cells against the tumor because mice that received both splenocytes and tumor cells (GVHD + LM + P815 group) presented with a similar survival rate as the LM-treated mice that received only splenocytes (LM group) (Figure 7). 
Figure 7. Lithothamnion muelleri extract (LM) treatment does not interfere with GVL in mice subjected to GVHD. GVHD was induced by the transfer of splenocytes from $(\mathrm{C} 57 \mathrm{BL} / 6 \mathrm{~J})$ donors to B6D2F1 mice. $\mathrm{GFP}^{+}$P815 cells were injected i.v. into B6D2F1 recipients on day 0 of transplantation. Mice that received only syngeneic (B6D2F1) splenocytes did not develop disease and were considered the Control group. The P815 group received only $\mathrm{GFP}^{+} \mathrm{P} 815$ cells, and the other groups received splenocytes from $(\mathrm{C} 57 \mathrm{BL} / 6 \mathrm{~J})$ donors as well as $\mathrm{GFP}^{+} \mathrm{P} 815$ cells. LM (1\% in the diet w/w) was offered in the diets of recipient mice from one day before transplantation until the experimental endpoint. After the induction of GVHD, the mice were evaluated every two days for survival. The results are shown as the mean \pm SEM. Control group $(\diamond), n=6$; GVHD group $(\boldsymbol{\square}), n=6$; LM group $(\boldsymbol{\nabla}), n=6$; P815 group $(\bullet), n=6$; GVHD + P815 group ( $\square), n=7$ and GVHD + LM + P815 group ( $\times), n=7 . *$ and ${ }^{\#}, p<0.05$ when compared with mice that received no tumor cells and mice that received tumor cells but were not subjected to GVHD, respectively.

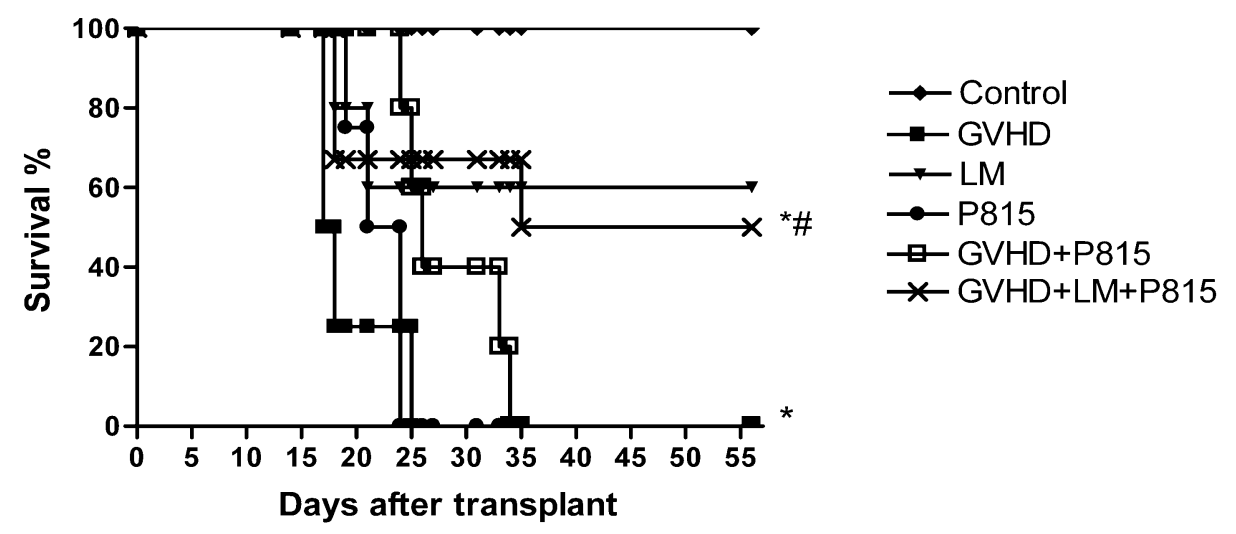

\section{Experimental Section}

\subsection{Mice}

Eight- to 12-week-old C57BL/6 and B6D2F1 (C57BL/6 $\times \mathrm{DBA} / 2)$ mice were obtained from the Centro de Bioterismo (UFMG, Belo Horizonte, Brasil) and housed under standard conditions in a temperature-controlled room $\left(23 \pm 1^{\circ} \mathrm{C}\right)$ on an automatic, 12-h light/dark cycle. Mice had free access to commercial chow and water. All animal care and experimental procedures were performed in accordance with the local Institutional Committee for Animal Care and Use (it is approved by protocol number: 120/09).

\subsection{Algal Material}

Extracts of L. muelleri were donated by the company Phosther Algamar (Belo Horizonte, Minas Gerais, Brazil) as a whitish granulate known as marine mineral concentrate. The granulate was produced by washing the seaweed sequentially with tap water and distilled water to remove salt and all visible epiphytes, following by crushing in a ball mill and drying in a ventilated oven. The species was identified by Maria Carolina M. de O. Henriques, Instituto Biodiversidade Marinha, Rio de Janeiro, Brazil. 


\subsection{Polysaccharide-Rich Fraction}

The polysaccharide-rich fraction (B2) was obtained as previously described [12]. Briefly, portions of the granulate were submitted to extraction with water at $60{ }^{\circ} \mathrm{C}$ for $6 \mathrm{~h}$ under mechanical stirring, using the proportion of $5 \%(\mathrm{w} / \mathrm{v})$ granulate in distilled water. After filtration, the remaining residue was reextracted sequentially with $1 \%$ and $2 \%(\mathrm{w} / \mathrm{v}) \mathrm{Na}_{2} \mathrm{CO}_{3}$ solution for $2 \mathrm{~h}$ at $60{ }^{\circ} \mathrm{C}(5 \% \mathrm{w} / \mathrm{v}$ material/solvent extractor), originating fractions B1 and B2 (final fraction used in this work), respectively. In the sequence, the extracts were concentrated in a rotatory evaporator and ethanol was added for polysaccharide precipitation. The precipitates were then dialyzed against water through a cellulose membrane and water was removed using a centrifugal vacuum concentrator. The chemical composition of B1 and B2 fractions has been previously investigated [12]. As stated in the mentioned publication, the chemical analysis of these fractions suggested related compositions, with similar contents of total carbohydrates $[(40.0 \pm 1.0) \%$ and $(38.8 \pm 0.9) \%$, respectively, for B1 and B2] and uronic acid $[(4.5 \pm 0.1) \%$ and $(4.6 \pm 0.1) \%]$, but differences in the concentrations of sulfate $[(3.6 \pm 0.9) \%$ and $(18.0 \pm 1.0) \%]$ and total proteins $[(6.0 \pm 1.0) \%$ and $(2.3 \pm 0.1) \%]$.

\subsection{Induction of GVHD}

\subsubsection{Partial Body Irradiation}

GVHD was induced by i.v. injection of $3 \times 10^{7}$ splenocytes from syngeneic (B6D2F1) or semiallogeneic (C57BL/6) donors into recipient B6D2F1 mice that had been irradiated with a single 4 Gy dose of partial body irradiation (source $\mathrm{CO}^{60}$ ) 2 days prior to transplantation, as described previously [34-36].

\subsubsection{Total Body Irradiation}

Recipient B6D2F1 mice were irradiated with 8 Gy total body irradiation (source $\mathrm{CO}^{60}$ ) in 2 doses at a $2 \mathrm{~h}$ interval to minimize gastrointestinal toxicity, followed by an i.v. infusion of $3 \times 10^{7}$ splenocytes and $1 \times 10^{7}$ bone morrow cells from syngeneic (B6D2F1) or semiallogeneic (C57BL/6) donors. In this model, due to the toxicity of total body irradiation, the recipient mice received an oral suspension of ciprofloxacin $(70 \mathrm{mg} / \mathrm{L})$ in their drinking water from 1 day before to 15 days after the transplantations.

\subsubsection{Cell Preparation}

Bone marrow suspensions were prepared by flushing femurs with Roswell Park Memorial Institute medium (RPMI)-1640 medium that was supplemented with 10\% fetal calf serum (FCS). Splenocytes were obtained by gently crushing spleens in complete medium to release the cells, which were then filtered to remove debris and washed twice in phosphate buffered saline (PBS) before injection.

\subsubsection{Experimental Groups}

B6D2F1 mice, which received splenocytes from B6D2F1 mice (B6D2F1 to B6D2F1), did not develop disease and were considered the control group. The GVHD, $\mathrm{LM}$ and $\mathrm{CaCO}_{3}$ groups received splenocytes from C57BL/6 mice (C57BL/6 to B6D2F1) and developed classic disease. 


\subsection{Therapies}

LM was administered at concentrations of $0.1 \%, 0.3 \%$, and $1 \% \mathrm{w} / \mathrm{w}$ in the diet of the LM group from 1 day before transplantation until the experimental endpoint. For the dietary preparations, $100 \mathrm{~g}$ of crushed diet were combined with $\mathrm{LM}$ at $0.1 \%, 0.3 \%$, or $1 \% \mathrm{w} / \mathrm{w}$ in $60 \mathrm{~mL}$ of filtered water to determine the dose response. The GVHD group received only crushed diet in $60 \mathrm{~mL}$ of filtered water. The $\mathrm{CaCO}_{3}$ group received a diet supplemented with $0.9 \% \mathrm{w} / \mathrm{w}$ of calcium carbonate, prepared similarly to the LM group. The effect of the LM polysaccharide-rich fraction was analyzed by intravital microscopy in mice that had been treated with a single dose of the fraction, $100 \mathrm{mg} / \mathrm{kg}$ in $200 \mu \mathrm{L}$ of PBS containing diluted ethanol in a concentration of $5 \%(\mathrm{v} / \mathrm{v})$, or $200 \mu \mathrm{L}$ of vehicle, PBS containing diluted ethanol in a concentration of $5 \%(\mathrm{v} / \mathrm{v}), 30 \mathrm{~min}$ before the experiment.

\subsection{Mortality Rate and Assessment of GVHD Clinical Score}

Mice were monitored daily for survival after the transplants and were evaluated clinically with a standard scoring system that generated a composite GVHD score from the individual scores for weight loss, posture (hunching), activity, fur texture, skin integrity, diarrhea, and faecal occult blood. A clinical index was subsequently generated by the summation of the seven criteria scores (maximum index $=14$ ), as described previously [34-36].

\subsection{Histopathology}

A set of experiments was conducted to quantify the histopathological parameters in the intestine and liver, which are important GVHD target organs. Tissue sections were processed for histological analysis as described previously [34] and were evaluated by a pathologist. A numerical value was attributed to the changes observed in the intestinal layers (mucosa, lamina propria, muscular, and serosa) or in the liver (degenerative alterations of parenchyma) were evaluated and each animal received a score that was generated by a summation of all observed changes (maximum index: 9 for intestine and 6 for liver) as described in Castor et al. [34]. Histopathological scores were determined for the samples that were obtained from mice at day 20 after the transplant, which corresponded to the clinical disease mortality phase in mice. The intestines and livers were removed for histopathological analysis from some mice at $24 \mathrm{~h}$ after irradiation and before transplantation to control for the consequences of irradiation to these organs. Significant pathological changes were not detected at this time-point (data not shown).

\subsection{Periodic Acid-Schiff (PAS) Staining}

After the induction of GVHD, the mice were sacrificed at day 20 after transplantation. The intestines (jejunum-ileum) were processed for histological analysis as described previously [34] and were stained with Periodic Acid-Schiff. The numbers of PAS-positive goblet cells were counted in four fields per intestine at $40 \times /$ field, and a mean number/field was calculated for each sample. 


\subsection{Quantification of Macrophage Infiltration}

The relative numbers of infiltrating macrophages in the intestine and liver were quantified by measuring the $N$-acetyl glucosaminidase (NAG) activity at day 20 after transplantation. A $100 \mathrm{mg}$ portion of the small intestine was resuspended in $0.9 \%$ saline $\left(4{ }^{\circ} \mathrm{C}\right)$ with $0.15 \mathrm{v} / \mathrm{v}$ Triton X-100 (Merck, Rahway, NJ, USA), homogenized, and centrifuged at $4{ }^{\circ} \mathrm{C}$ for $10 \mathrm{~min}$ at $1500 \mathrm{rpm}$. The supernatants were collected and assayed immediately for NAG activity at a 1:10 dilution as described previously [57].

\subsection{Bacterial Translocation}

At day 20 after transplantation, $100 \mu \mathrm{L}$ of blood, $100 \mu \mathrm{L}$ of peritoneal lavage fluid, and $100 \mathrm{mg}$ of liver homogenate were plated onto Muller Hilton plates. These plates were incubated for $24 \mathrm{~h}$ at $37^{\circ} \mathrm{C}$ and the numbers of bacterial colonies were counted and expressed as colony-forming unit (CFU).

\subsection{Quantification of Cytokines and Chemokines}

The concentrations of cytokines and chemokines were quantified from intestinal or liver homogenates from animals at days 3, 10, and 20 after transplantation. The tissues were mixed with PBS that contained antiproteases $(0.1 \mathrm{mM}$ phenylmethanesulfonylfluoride (PMSF); $0.1 \mathrm{nM}$ benzethonium chloride; $10 \mathrm{mM}$ ethylenediamine tetraacetic acid (EDTA); 20 Kallikrein Inhibitor Units (KIU), aprotinin A) and $0.05 \%$ Tween 20. Next, the samples were centrifuged for $10 \mathrm{~min}$ at $10,000 \mathrm{rpm}$ and $4{ }^{\circ} \mathrm{C}$. Dilutions of the supernatants in PBS (1:4) were immediately analyzed by ELISA. The cytokines and chemokines concentrations were measured according to the manufacturer's procedures (R \& D Systems, Minneapolis, MN, USA) and the colorimetric reactions were analyzed with a spectrophotometer at a wavelength of $492 \mathrm{~nm}$.

\subsection{Intravital Microscopy}

GVHD was induced in B6D2F1 mice by the transplantation of C57BL/6 splenocytes. At day 10 after transplantation, the mice were anesthetized and the intestinal venules were exposed in a perfusion system with warm bicarbonate-buffered saline ( $\mathrm{pH} 7.4)$. For intravital microscopy analysis, mice that had received C57BL/6 splenocytes were treated with a single $200 \mu \mathrm{L}$ dose of the vehicle (PBS-5\% ethanol) or LM polysaccharide-rich fraction (B2, $100 \mathrm{mg} / \mathrm{kg}$ in $200 \mu \mathrm{L}$ of PBS-5\% ethanol) at $30 \mathrm{~min}$ before the intravital microscopic analysis. The fraction was administered just prior to the intravital procedure to prevent any changes to the local production of proinflammatory mediators. In the control group, B6D2F1 mice received B6D2F1 splenocytes. An intravital microscope (ECLIPSE 50i, Nikon, Japan) with a 20 objective lens was used to examine the mesenteric microcirculation. A digital camera (DS-QilMC, Nikon, Japan) was used to project the images onto a computer monitor, and the images were recorded for playback analysis with Nikon Imaging Software (Nikon, Kawasaki, Japan). The intestinal venules 40-60 $\mu \mathrm{m}$ were selected and the numbers of rolling and adherent leukocytes were determined off-line during the video-playback analysis. Rolling leukocytes were defined as those cells that moved at a velocity less than that of the erythrocytes within a given vessel. The flux of rolling cells was measured as the number of rolling cells that passed by a given point in the venule per minute. 
A leukocyte was considered to be adherent if it remained stationary for at least $30 \mathrm{~s}$, and total leukocyte adhesion was quantified as the number of adherent cells in the intravascular space within an area of $100 \mu \mathrm{m}$.

\subsection{GVL Induction}

A P815 mouse mastocytoma cell line (H-2 ${ }^{\mathrm{d}}$; American Type Culture Collection, Manassas, VA, USA) that had been transduced with a lentiviral vector (elongation factor 1-GFP) was kindly provided by Anna C. Leal and Martin Bonamino (Instituto Nacional do Câncer, Rio de Janeiro, Brazil). This cell line was maintained in RPMI/10\% FCS at $37{ }^{\circ} \mathrm{C}$ and $5 \% \mathrm{CO}_{2}$ and was used for GVL (graft-versus-leukaemia) experiments in vivo. The above-described protocols for irradiation and GVHD induction were used. B6D2F1 recipients were injected i.v. with $10^{4} \mathrm{GFP}^{+}$P815 cells on day 0 of the transplantation experiment. After the induction of GVHD and transplantation of tumor cells, the mice were monitored every two days for survival. LM was offered in the diets of recipient mice from one day before transplantation until the experimental endpoint.

\subsection{Statistical Analysis}

Data in the text are expressed as the mean \pm SEM. Comparisons between the groups were performed by ANOVA, followed by the Student Newman-Keuls post hoc analysis. A log-rank test was used to compare the relevant survival curves. Statistical significance was set as $p<0.05$, and all graphs and analysis were performed with GraphPad Prism 4 software (GraphPad Software Inc., San Diego, CA, USA).

\section{Conclusions}

The present study evaluated the effects of treatment with the alga Lithothamnion muelleri in the pathogenesis of acute graft-versus-host disease. In summary, we have demonstrated that LM treatment reduced intestinal and hepatic injuries, bacterial translocation, and macrophage accumulation after the transplantation of $\mathrm{C} 57 \mathrm{Bl} / 6$ mice splenocytes into B6D2F1 mice. Additionally, LM treatment was accompanied with reduced production of pro-inflammatory mediators, including TNF- $\alpha$, IFN- $\gamma$, CCL2, CCL3, and CCL5. Decreased leukocyte accumulation was associated with the anti-inflammatory effects of sulphated polysaccharides that were extracted from LM and which interfered with leukocyte-endothelium interactions in the intestinal venules as determined by intravital microscopy. Importantly, LM treatment resulted in reduced manifestations of GVHD in both animal models (partial or total body irradiation) as determined by reductions in the lethality rates and clinical scores. Finally, LM treatment did not interfere with the beneficial effects of the graft against the $\mathrm{GFP}^{+} \mathrm{P} 815$ leukaemia cell line. Thus, the results presented herein reveal Lithothamnion muelleri as a new candidate with potential therapeutic applications for the treatment of graft-versus-host disease.

\section{Acknowledgments}

This work was supported by grants from Coordenação de Aperfeiçoamento de Pessoal do Ensino Superior (CAPES, Brasília, Brazil), Conselho Nacional de Desenvolvimento Científico e Tecnológico 
(CNPq, Brasília, Brazil)—Brazilian Foundation for Trainning, Fundação de Amparo à Pesquisa do Estado de Minas Gerais (Fapemig, Belo Horizonte, Brazil)—Minas Gerais Foundation for Research, the company Phoster Algamar (Rio de Janeiro, Brazil) and European Community's Seventh Framework Programme (FP7-2007-2013) under grant agreement HEALTH-F4-2011-281608.

\section{Conflict of Interest}

The authors declare no conflict of interest.

\section{References}

1. Ferrara, J.L.; Levine, J.E.; Reddy, P.; Holler, E. Graft-versus-host disease. Lancet 2009, 373, $1550-1561$.

2. Pasquini, M.C.; Wang, Z.; Horowitz, M.M.; Gale, R.P. 2010 report from the Center for International Blood and Marrow Transplant Research (CIBMTR): Current uses and outcomes of hematopoietic cell transplants for blood and bone marrow disorders. Clin. Transpl. 2010, 2010, 87-105.

3. Goker, H.; Hanznedaroglu, I.C.; Chao, N.J. Acute graft-versus-host disease: Pathobiology and management. Exp. Hematol. 2001, 29, 259-277.

4. Socié, G.; Blazar, B.R. Acute graft-versus-host disease: From the bench to the bedside. Blood 2009, 114, 4327-4336.

5. Westin, J.R.; Saliba, R.M.; de Lima, M.; Alousi, A.; Hosing, C.; Qazilbash, M.H.; Khouri, I.F.; Shpall, E.J.; Anderlini, P.; Rondon, G.; et al. Steroid-refractory acute GVHD: Predictors and outcomes. Adv. Hematol. 2011, 2011, 1-8.

6. Martin, P.J.J.; Rizzo, D.; Wingard, J.R.; Ballen, K.; Curtin, P.T.; Cutler, C.; Litzow, M.R.; Nieto, Y.; Savani, B.N.; Schriber, J.R.; et al. First- and second-line systemic treatment of acute graft-versus-host disease: Recommendations of the american society of blood and marrow transplantation. Biol. Blood Marrow Transpl. 2012, 18, 1150-1163.

7. Wolf, D.; von Lilienfeld-Toal, M.; Wolf, A.M.; Schleuning, M.; von Bergwelt-Baildon, M.; Held, S.A.; Brossart, P. Novel treatment concepts for graft-versus-host disease. Blood 2012, 119, $16-25$.

8. Blazar, B.R.; Murphy, W.J.; Abedi, M. Advances in graft-versus-host disease biology and therapy. Nat. Rev. Immunol. 2012, 12, 443-458.

9. Mayer, A.M.S.; Rodríguez, A.D.; Berlinck, R.G.S.; Fusetani, N. Marine pharmacology in 2007-2008: Marine compounds with antibacterial, anticoagulant, antifungal, anti-inflammatory, antimalarial, antiprotozoal, antituberculosis, and antiviral activities; affecting the immune and nervous system, and other miscellaneous mechanisms of action. Comp. Biochem. Physiol. C 2011, $153,191-222$.

10. Faulkner, D.J. Marine natural products. Nat. Prod. Rep. 2000, 17, 1-57.

11. Blunt, J.W.; Copp, B.R.; Munro, M.H.G.; Northcotec, P.T.; Prinsep, M.R. Marine natural products. Nat. Prod. Rep. 2006, 23, 26-78. 
12. Soares, C.M.; Malagoli, B.G.; Menezes, G.B.; Pinho, V.; Souza, D.G.; Teixeira, M.M.; Braga, F.C. Antiadhesive activity of polysaccharide-rich fractions from Lithothamnion muelleri. Z. Naturforsch. C 2012, 67, 391-397.

13. Aslam, M.N.; Paruchuri, T.; Bhagavathula, N.; Varani, J. A mineral-rich red algae extract inhibits polyp formation and inflammation in the gastrointestinal tract of mice on a high-fat diet. Integr. Cancer Theory 2010, 9, 93-99.

14. Aslam, M.N.; Bergin, I.; Naik, M.; Hampton, A.; Allen, R.; Kunkel, S.L.; Rush, H.; Varani, J. A multi-mineral natural product inhibits liver tumor formation in C57BL/6 mice. Biol. Trace Elem. Res. 2012, 147, 267-274.

15. Derrien, M.; van Passel, M.W.J.; van de Bovenkamp, J.H.B.; Schipper, R.G.; de Vos, W.M.; Dekker, J. Mucin-bacterial interactions in the human oral cavity and digestive tract. Gut Microb. 2010, 1, 254-268.

16. Johansson, M.E.; Ambort, D.; Pelaseved, T.; Schütte, A.; Gustafsson, J.K.; Ermund, A.; Subramani, D.B.; Holmén-Larsson, J.M.; Thomsson, K.A.; Bergström, J.H.; et al. Composition and functional role of the mucus layers in the intestine. Cell. Mol. Life Sci. 2011, 68, 3635-3641.

17. Barnett, A.M.; Roy, N.C.; Mc Nabb, W.C.; Cookson, A.L. The interactions between endogenous bacteria, dietary components and the mucus layer of the large bowel. Food Funct. 2012, 3, 690-699.

18. Hong, I.H.; Ji, H.; Hwa, S.Y.; Jeong, W.I.; Jeong, D.H.; Do, S.H.; Kim, J.M.; Ki, M.R.; Park, J.K.; Goo, M.J.; et al. The protective effect of ENA actimineral resource A on $\mathrm{CCl}$ 4-induced liver injury in rats. Mar. Biotechnol. 2011, 13, 462-473.

19. Robb, R.J.; Hill, G.R. The interferon-dependent orchestration of innate and adaptive immunity after transplantation. Blood 2012, 119, 5351-5358.

20. Tuncer, H.H.; Rana, N.; Milani, C.; Darko, A.; Al-Homsi, S.A. Gastrointestinal and hepatic complications of hematopoietic stem cell transplantation. World J. Gastroenterol. 2012, 18, 1851-1860.

21. Hill, G.R.; Ferrara, J.L. The primacy of the gastrointestinal tract as a target organ of acute graft-versus-host disease: Rationale for the use of cytokine shields in allogeneic bone marrow transplantation. Blood 2000, 95, 2754-2759.

22. Jones, J.M.; Wilson, R.; Bealmear, P.M. Mortality and gross pathology of secondary disease in germfree mouse radiation chimeras. Radiat. Res. 1971, 45, 577-588.

23. Beelen, D.W.; Haralambie, E.; Brandt, H.; Linzenmeier, G.; Muller, K.D.; Quabeck, K.; Sayer, H.G.; Graeven, U.; Mahmoud, H.K.; Schaefer, U.W. Evidence that sustained growth suppression of intestinal anaerobic bacteria reduces the risk of acute graft-versus-host disease after sibling marrow transplantation. Blood 1992, 80, 2668-2676.

24. Beelen, D.W.; Elmaagacli, A.; Muller, K.D.; Hirche, H.; Schaefer, U.W. Influence of intestinal bacterial decontamination using metronidazole and ciprofloxacin or ciprofloxacin alone on the development of acute graft-versus-host disease after marrow transplantation in patients with hematologic malignancies: Final results and long-term follow-up of an open-label prospective randomized trial. Blood 1999, 93, 3267-3275. 
25. Irani, J.L.; Cutler, C.S.; Whang, E.E.; Clancy, T.E.; Russel, S.; Swanson, R.S.; Ashley, S.W.; Zinner, M.J.; Raut, C.P. Severe acute gastro-intestinal graft-vs.-host disease: An emerging surgical dilemma in contemporary cancer care. Arch. Surg. 2008, 143, 1041-1045.

26. Cooke, K.R.; Gerbitz, A.; Crawford, J.M.; Teshima, T.; Hill, G.R.; Tesolin, A.; Rossignol, D.P.; Ferrara, J.L. LPS antagonism reduces graft-versus-host disease and preserves graft-versus-leukemia activity after experimental bone marrow transplantation. J. Clin. Invest. 2001, 107, 1581-1589.

27. Lang, T.; Hansson, G.C.; Samuelsson, T. Gel forming mucins appeared early in metazoan evolution. Proc. Natl. Acad. Sci. USA 2007, 104, 16209-16214.

28. Fieren, M.W. The local inflammatory responses to infection of the peritoneal cavity in humans: Their regulation by cytokines, macrophages, and other leukocytes. Mediat. Inflamm. 2012, 2012, $1450-1462$.

29. Serody, J.S.; Burkett, S.E.; Panoskaltsis-Mortari, A.; Ng-Cashin, J.; McMahon, E.; Matsushima, G.R.; Lira, S.A.; Cook, D.N.; Blazar, B.R. T-Lymphocyte production of macrophage inflammatory protein-1 is critical to recruitment of CD8T cells to the liver, lung, and spleen during graft-versus-host disease. Blood 2000, 96, 2973-2980.

30. Wysocki, C.A.; Panoskalsis-Mortari, A.; Blazar, B.R.; Serody, J.S. Leukocyte migration and graft-versus-host disease. Blood 2005, 105, 4191-4199.

31. Jaksch, M.; Mattsson, J. The pathophysiology of graft-versus-host disease. Scand. J. Immunol. 2005, 61, 398-409.

32. Choi, S.W.; Hildebrandt, G.C.; Olkiewicz, K.M.; Hanauer, D.A.; Chaudhary, M.N.; Silva, I.A.; Rogers, C.E.; Deurloo, D.T.; Fisher, J.M.; Liu, C.; et al. CCR1:CCL5 (RANTES) receptor ligand interactions modulates allogeneic $\mathrm{T}$ cell responses and reduces graft-versus-host disease following stem cell transplantation. Blood 2007, 110, 3447-3455.

33. Bouazzaoui, A.; Spacenko, E.; Muller, G.; Miklos, S.; Huber, E.; Holler, E.; Andreesen, R.; Hildebrandt, G.C. Chemokine and chemokine receptor expression analysis in target organs of acute graft-versus-host disease. Genes Immun. 2009, 10, 687-701.

34. Castor, M.G.; Rezende, B.; Resende, C.B.; Alessandri, A.L.; Fagundes, C.T.; Sousa, L.P.; Arantes, R.M.; Souza, D.G.; Silva, T.A.; Proudfoot, A.E.; et al. The CCL3/macrophage inflammatory protein-1-binding protein evasin-1 protects from graft-versus-host disease but does not modify graft-versus-leukemia in mice. J. Immunol. 2010, 184, 2646-2654.

35. Castor, M.G.M.; Rezende, B.; Bernardes, P.T.T.; Vieira, T.A.; Arantes, R.M.E.; Souza, D.G.; Silva, T.A.; Teixeira, M.M.; Pinho, V. PI3K controls leukocyte recruitment, tissue injury and lethality in a model of graft versus host disease in mice. J. Leukoc. Biol. 2011, 89, 955-964.

36. Castor, M.G.M.; Rezende, B.M.; Resende, C.B.; Bernardes, P.T.; Cisalpino, D.; Vieira, A.T.; Souza, D.G.; Silva, T.A.; Teixeira, M.M.; Pinho, V. Platelet-activating factor receptor plays a role in the pathogenesis of graft-versus-host disease by regulating leukocyte recruitment, tissue injury, and lethality. J. Leukoc. Biol. 2012, 89, 629-639.

37. Castor, M.G.M.; Pinho, V.; Teixeira, M.M. The role of chemokines in mediating graft versus host disease: Opportunities for novel therapeutics. Front. Pharmacol. 2012, 3, 1-13.

38. Terwey, T.H.; Kim, T.D.; Kochman, A.A.; Hubbard, V.M.; Lu, S.; Zakrzewski, J.L. CCR2 is required for CD8-induced graft-versus-host disease. Blood 2005, 106, 3322-3330. 
39. Piguet, P.F.; Grau, G.E.; Allet, B.; Vassalli, P. Tumor necrosis factor/cachectin is an effector of skin and gut lesions of the acute phase of graft-versus-host disease. Exp. Med. 1987, 166, 1280-1289.

40. Backer, M.B.; Altman, N.H.; Podack, E.R.; Levy, R.B. The role of cell-mediated cytotoxicity in acute GVHD after MHC-matched allogeneic bone marrow transplantation in mice. J. Exp. Med. 1996, 183, 2645-2656.

41. Koide, S.; McVay, L.D.; Frankel, W.L.; Betling, C.A.; Zhou, E.D.; Shimada, T.; Zhang, W.; Rombeau, J.L. Increased expression of tissue cytokines in graft-versus-host disease after small bowel transplantation in the rat. Transplantation 1997, 64, 518-524.

42. Schroeder, M.A.; DiPersio, J.F. Mouse models of graft-versus-host disease: Advances and limitations. Dis. Model. Mech. 2011, 4, 318-333.

43. Dias, C.T.M. Granulados bioclásticos-Algas calcárias. Rev. Bras. Geof. 2000, 8, 307-318.

44. Dame, M.K.; Veerapaneni, I.; Bhagavathula, N.; Naik, M.; Varani, J. Human colon tissue in organ culture: Calcium and multi-mineral-induced mucosal differentiation. In Vitro Cell. Dev. Biol. Anim. 2011, 47, 32-38.

45. Matsui, M.S.; Muizzuddin, N.; Arad, S.; Marenus, K. Sulfated polysaccharides from red microalgae have antiinflammatory properties in vitro and in vivo. Appl. Biochem. Biotechnol. 2003, 104, 13-22.

46. Jiao, G.; Yu, G.; Zhang, J.; Ewart, H.S. Chemical structures and bioactivities of sulfated polysaccharides from marine algae. Mar. Drugs 2011, 9, 196-223.

47. Hill, G.R.; Crawford, J.M.; Cooke, K.R.; Brinson, Y.S.; Pan, L.; Ferrara, J.L. Total body irradiation and acute graft-versus-host disease: The role of gastrointestinal damage and inflammatory cytokines. Blood 1997, 90, 3204-3213.

48. Cooke, K.R.; Hill, G.R.; Crawford, J.M.; Bungard, D.; Brinson, Y.S.; Delmonte, J.J.; Ferrara, J.L. Tumor necrosis factor- $\alpha$ production to lipopolysaccharide stimulation by donor cells predicts the severity of experimental acute graft-versus-host disease. J. Clin. Invest. 1998, 102, 1882-1891.

49. Howard, J.G.; Woodruff, M.F.A. Effect of the graft-versus-host reaction on the immunological responsiveness of the mouse. Proc. R. Soc. Lond. 1961, 154, 532-539.

50. Horowitz, M.M.; Gale, R.P.; Sondel, P.M.; Goldman, J.M.; Kersey, J.; Kolb, H.J.; Rimm, A.A.; Ringden, O.; Rozaman, C.; Speck, B.; et al. Graft-versus-leukemia reactions after bone marrow transplantation. Blood 1990, 75, 555-561.

51. Johnson, B.D.; Hanke, C.A.; Truitt, R.L. The graft-versus-leukemia effect of post-transplant donor leukocyte infusion. Leuk. Lymphoma 1996, 23, 1-9.

52. Matejková, E.; Ocadlíková, D.; Smejkalová, J.; Muzíkova, J.; Raida, L.; Tousovská, K.; Pacasová, R.; Nenicková, M.; Tesarová, E.; Sterba, J.; et al. Selective depletion of alloreactive T cells and study of anti-tumor activity of specific $\mathrm{T}$ cell clones in patients with leukemia. Klin. Onkol. 2008, 21, 104-109.

53. Li, J.M.; Giver, C.R.; Lu, Y.; Hossain, M.S.; Akhtari, M.; Waller, E.K. Separating graft-versus-leukemia from graft-versus-host disease in allogeneic hematopoietic stem cell transplantation. Immunotherapy 2009, 1, 599-621. 
54. Dazzi, F.; Szydlo, R.M.; Goldman, J.M. Donor lymphocyte infusions for relapse of chronic myeloid leukemia after allogeneic stem cell transplant: Where we now stand. Exp. Hematol. 1999, 27, 1477-1486.

55. Porter, D.L.; Antin, J.H. The graft-vs.-leukemia effects of allogeneic cell therapy. Annu. Rev. Med. 1999, 50, 369-386.

56. Xia, G.; Truitt, R.L.; Johnson, B.D. Graft-versus-leukemia and graft-versus-host reactions after donor lymphocyte infusion are initiated by host-type antigen-presenting cells and regulated by regulatory $\mathrm{T}$ cells in early and long-term chimeras. Biol. Blood Marrow Transpl. 2006, 12, $397-407$.

57. Barcelos, L.S.; Talvani, A.; Teixeira, A.S.; Cassali, G.D.; Andrade, S.P.; Teixeira, M.M. Production and in vivo effects of chemokines CXCL1-3/KC and CCL2/JE in a model of inflammatory angiogenesis in mice. Inflamm. Res. 2004, 53, 576-584.

(C) 2013 by the authors; licensee MDPI, Basel, Switzerland. This article is an open access article distributed under the terms and conditions of the Creative Commons Attribution license (http://creativecommons.org/licenses/by/3.0/). 